\title{
Mechanism Study on the Axial Compressive Performance of Short Square CFST Columns with Different Stiffeners
}

\author{
Bing Xu $(\mathbb{D}$, Fahong Wu, and Guizhong Xu $(\mathbb{D}$ \\ Civil Engineering Department of Yancheng Institute of Technology, Yancheng 224051, China \\ Correspondence should be addressed to Bing Xu; bateren@126.com
}

Received 11 March 2018; Revised 26 July 2018; Accepted 29 August 2018; Published 21 October 2018

Academic Editor: Yanchao Shi

Copyright (c) 2018 Bing Xu et al. This is an open access article distributed under the Creative Commons Attribution License, which permits unrestricted use, distribution, and reproduction in any medium, provided the original work is properly cited.

\begin{abstract}
In order to limit the disengaging of short square concrete-filled steel tube (CFST) columns and strengthen the combined action of steel tubes and concrete, a reinforcing method of stiffener is put forward in this paper. The axial compression performance and mechanism are studied through experiments, which indicate that (1) the buckling model of stiffening members changes into double wave, (2) stiffeners enforce the constraint in core concrete, (3) stiffeners can effectively improve the ultimate bearing capacity, (4) the stiffeners increase the stress in the middle of the steel tube and improve the distribution of stress for the core concrete, and (5) the direct ribs have more influence on the bearing capacity while ribs with holes have more impact on the deformation of the tube. At the end of the article, a formula for calculating the ultimate bearing capacity is presented, which can bring out a more accurate bearing capacity value.
\end{abstract}

\section{Introduction}

With the restriction of steel tube on the core concrete, the concrete-filled steel tube (CFST) members can achieve higher bearing capacity under the condition of finite section size $[1,2]$. CFST members are widely used as members subjected to axial force in large engineering structures, square and circle sections being the usual forms. In practical use of the square section, it is found that the corner concrete is subjected to a large binding effect in CFST, while the concrete in the middle of the side bears a relatively small restriction effect, and the whole confinement effect is weaker than that of circle section. The steel plate buckles easily under the axial force resulting in the disengaging of square CFST in the position of the bulging, which subsequently makes the steel tube lose its constraint on the core concrete and reduces the compressive capacity significantly. In addition, the different thermal performance, the shrinkage, and the creep of concrete also easily lead to the interface debonding of steel and concrete, which will affect the combined effect of CFST [3] and Wan [4]. Yang et al. [5] quantitatively analyzed the influence of disengaging ratio on the members, and the analysis showed that the ultimate bearing capacity of the members was reduced by over $20 \%$ when the disengaging ratio of the section was greater than $2 \%$, and the constraint effect of the steel tube on the core concrete was weakened or even lost. In order to enhance the adhesion between sections and the combination of steel tube and concrete, Cai et al. [6], Chen and Zhang [7, 8], Lei [9], Wan [4], and Zhu [10] have put forward many methods to strengthen the steel plate against buckling, such as local pull bars, stiffening ribs, and so on. For the purpose of improving the restraint effect of CFST, Cai and Long [11], Huang et al. [12], Liu and Guo [13], Petrus et al. [14], Yang et al. [5], and Chen [15] have proposed a method to improve the local buckling of steel plate with stiffened ribs. Liang and Lu [16] also proposed to enhance the performance of steel-mixed connection by setting shear parts inside the steel tube.

In order to limit the adverse effects of the disengaging between steel and concrete and strengthen the connection between steel and concrete, this paper proposes a method for stiffening by using straight ribs with or without holes. The axial loading test was done to verify the performance of the combined effect of short CFST columns with ribs. The contribution of steel tube and concrete to the bearing 

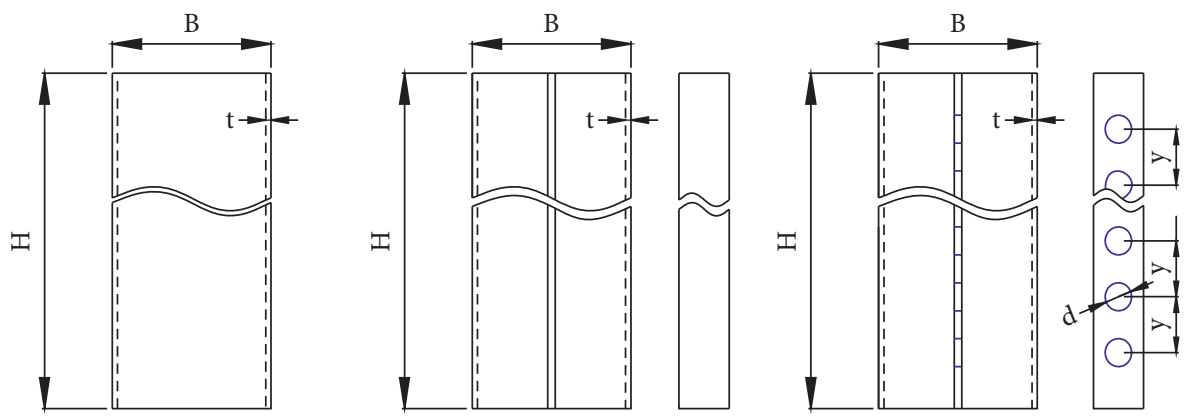

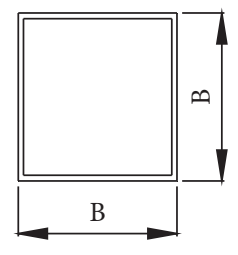

Type-A

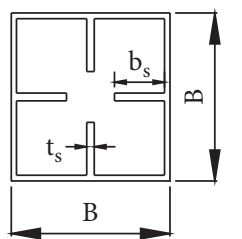

Type-B

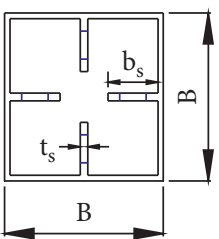

Type-C

Figure 1: Detail drawings of the specimen.

capacity of short columns and the stress on the cross section is analyzed, using FEA method. Based on the analysis of the mechanism of reinforced short square CFST columns, a formula for calculating the ultimate bearing capacity is presented, which can bring out a more accurate bearing capacity value.

\section{Test Survey}

2.1. Specimens Expression. Through a large number of experimental studies, Vana (2013) has found the size, and the distance of holes on the rib must meet the requirements of structures. Oguejiofor and Hosain [17] pointed out the distance between the holes on the ribs should be at least 2.25 times the diameter of the hole.

In this test, the diameter of holes was set half the width of the rib, and the spacing between holes was twice the diameter of the hole. The construction details and dimension parameters of specimens are shown in Figure 1 and Table 1. The steel was Q345, and the measured yield strength was $414 \mathrm{MPa}$ (thickness $=3 \mathrm{~mm}$ ), $464 \mathrm{Mpa}$ (thickness $=4 \mathrm{~mm}$ ), and $414 \mathrm{Mpa}$ (thickness $=8 \mathrm{~mm}$ ). The $f_{c u}$ of concrete was $55.6 \mathrm{Mpa}$ and its elastic modulus was $3550 \mathrm{Mpa}$.

2.2. Loading Condition. The loading process included loading control stage and displacement control stage. In the loading stage controlled by force, the step loading is $0.1 * N_{u}$ ( $N_{u}$ is the theoretical bearing capacity), the loading rate of each stage was $3 \mathrm{kN} / \mathrm{s}$, and the pressure was maintained for 5 minutes. When the load reached $70 \%$ of the estimated load, the loading control mode was changed to the displacement loading control, and the loading rate was $2 \mathrm{~mm} / \mathrm{min}$. When the bearing capacity of the specimen dropped to $75 \%$ of the ultimate bearing capacity of the specimen, the test stopped.
TABLE 1: Details of specimens (mm).

\begin{tabular}{lccccccc}
\hline Specimen number & $H$ & $B$ & $t$ & $b_{s}$ & $t_{s}$ & $d$ & $y$ \\
\hline SCA-1 & & & & - & - & - & - \\
SCB-1 & 900 & 300 & 4 & 90 & 4 & - & - \\
SCC-1 & & & & 90 & 4 & 45 & 100 \\
\hline SCA-2 & & & & - & - & - & - \\
SCB-2 & 900 & 300 & 3 & 90 & 3 & - & - \\
SCC-2 & & & & 90 & 3 & 45 & 100 \\
\hline SCA-3 & & & & - & - & - & - \\
SCB-3 & 900 & 300 & 8 & 90 & 8 & - & - \\
SCC-3 & & & & 90 & 8 & 45 & 100 \\
\hline
\end{tabular}

\section{Experimental Phenomena and Analysis of Results}

3.1. Specimen Failure Mode. At the beginning of the test, the specimen did not show clear deformation. When the loading value reached $60 \% N_{u}$, the specimen made a slight sound of breakage, and granules of rust dropped down from the surface. When the loading value reached $70 \% N_{u}$, clearly visible slip-lines occurred on the steel tube. With the load continued, a buckling occurred in the central position of slip-lines. After the largest load, the loading curve began to decrease rapidly, while the degree and the range of the buckling increased fast at the same time. A number of parallel buckling began to appear on all the sides of the tube; the deformations began to spread on each side.

Figure 2 shows the final failure shape of the three kinds of specimens. It indicated that: with axial loading, outward buckling deformation occurred on the steel tube. The specimen of type-A showed only one buckling deformation (single wave) at the same side of the same cross section. Type-B and type-C showed two rows of buckling deformation on the same cross section (double wave), while the peaks of these two types intersected with each other. And 


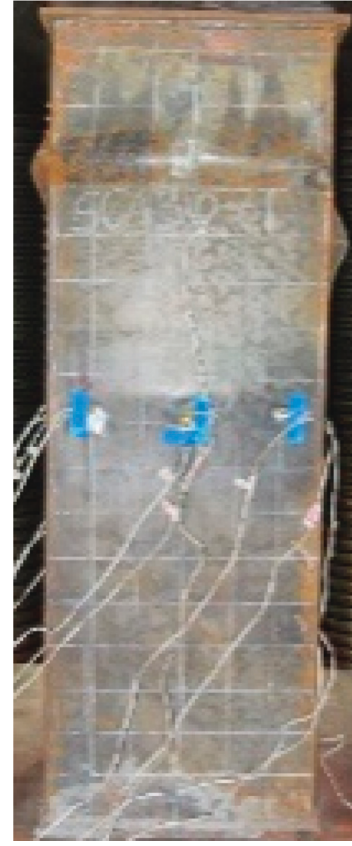

(a)

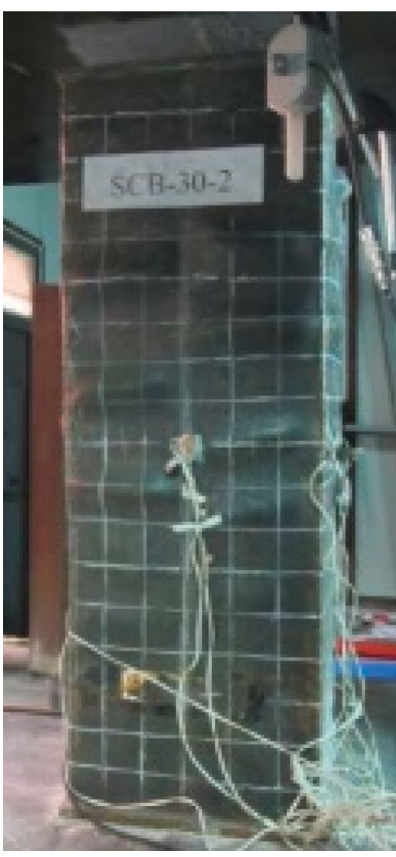

(b)

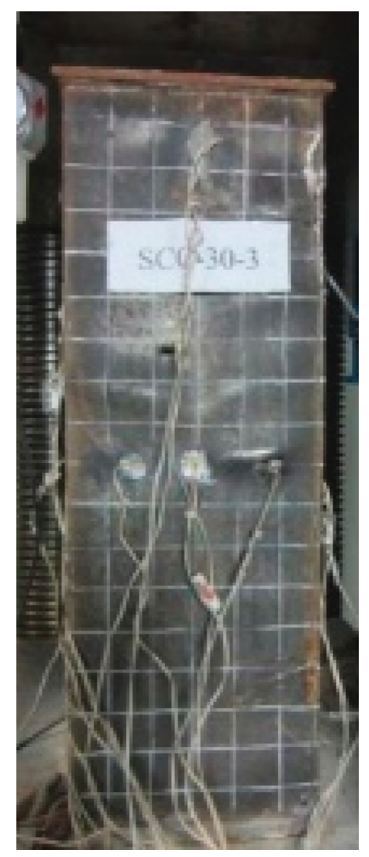

(c)

Figure 2: Buckling mode of the steel tube. (a) Type-A. (b) Type-B. (c) Type-C.

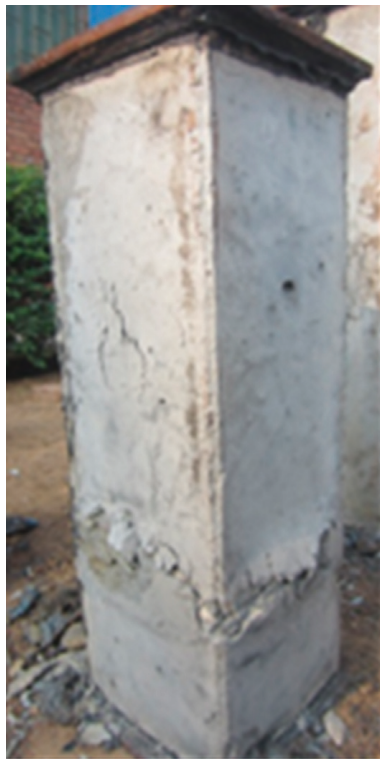

(a)

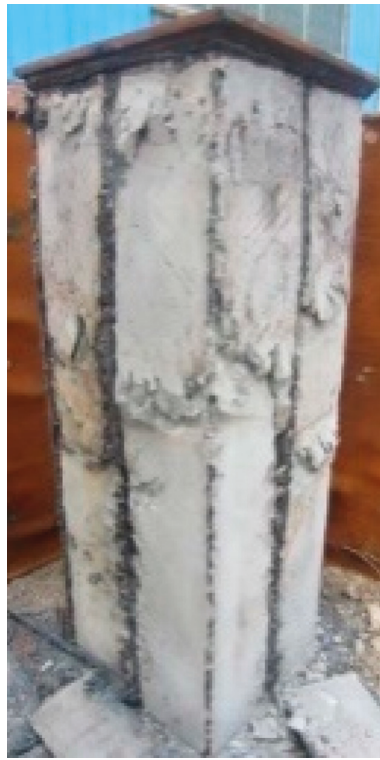

(b)

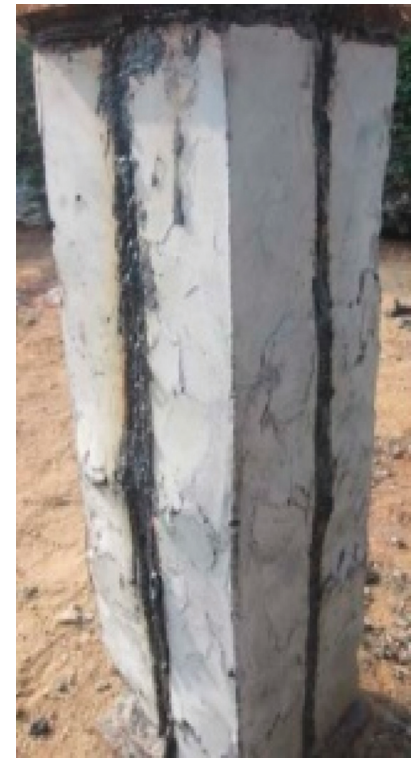

(c)

Figure 3: Core concrete failure of the specimens. (a) Type-A. (b) Type-B. (c) Type-C.

there were obviously more buckling lines on type- $C$ than on type- $\mathrm{B}$. In addition, the buckling lines on the neighboring side met on corners, and this phenomenon occurred on all the three types of specimen.

In order to analyze the failure of concrete inside the tube, the steel tube of the specimen was cut after the test, as shown in Figure 3. From this figure, it could be seen that the damage location of concrete corresponded with the position of the buckling on the tube. In type- $\mathrm{B}$, the stiffener divided the core concrete into four zones (see Figure 1). The failure area in each zone was connected to each other, while the damages in different zones were independent of each other. In type-C, concrete inside was also divided into four zones by stiffeners, but failure areas occurred parallel in each zone and parallel with those in neighboring zones, and the number and range of the failure were larger than those in type-B. 


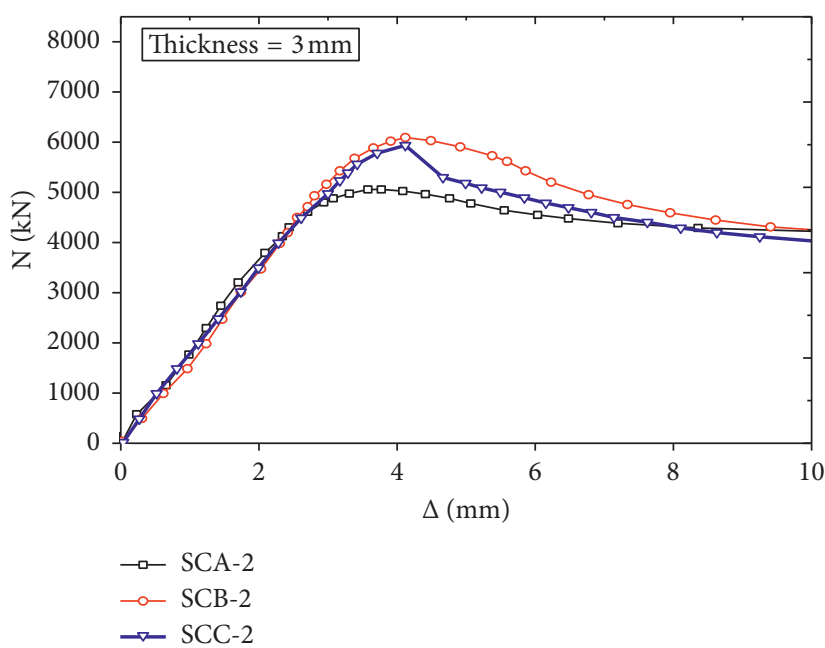

(a)

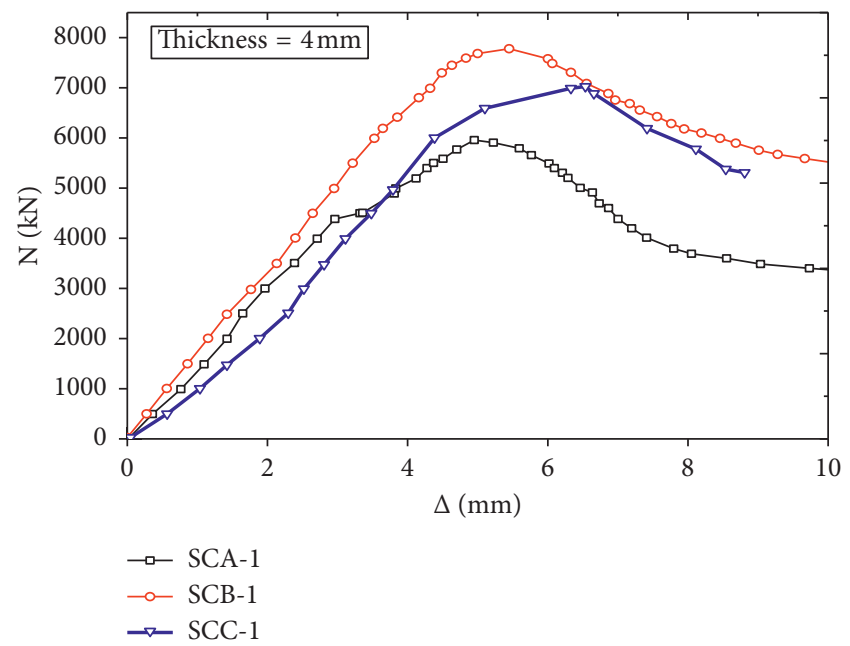

(b)

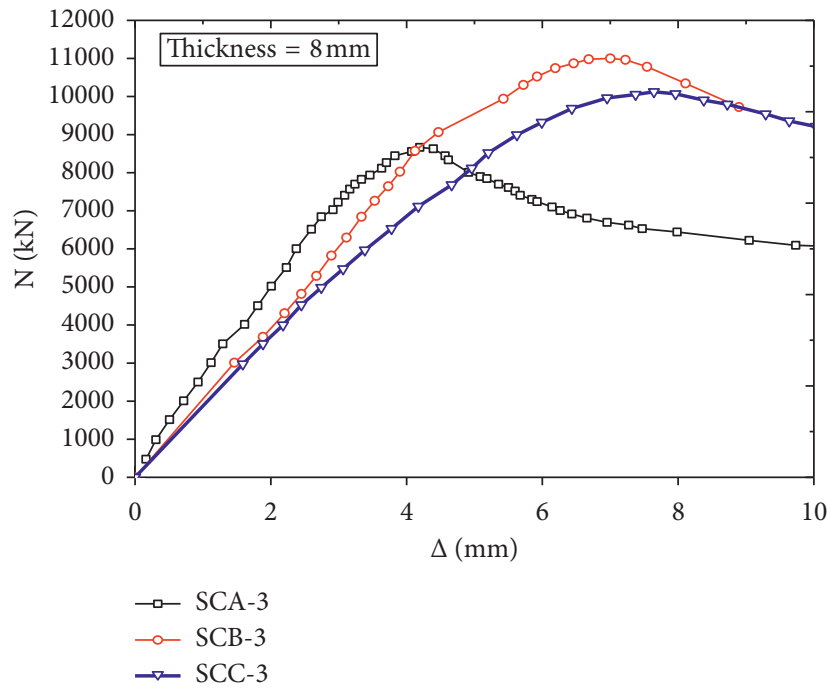

(c)

Figure 4: Load-displacement curves of specimens.

3.2. Load-Displacement Curve Analysis. In order to analyze the effect of stiffening mode on the bearing capacity and deformation capacity of short square CFST columns, the load-displacement curves of each specimen are presented in Figure 4, and the data are given in Table 2.

It could be seen from the load-displacement curves that (1) the ultimate bearing capacity could be effectively improved by the stiffening methods, in which the bearing capacity of type-B was increased by $20 \%$ at least, while the bearing capacity of type- $C$ was increased by $16.2 \%$ at least. The displacement was also increased by stiffeners, and the displacement of the B type specimen was increased by $6.21 \%$ at least, while it was increased by at least $11.4 \%$ in type-C. (2) The load-displacement curve showed that the secant stiffness of the load-displacement curve was lower than that of the type-A before type- $B$ and type- $C$ reached the top in the curves. The results showed that the axial compression stiffness of short square CFST columns was weakened to some extent, and the axial compression stiffness of type-A was greater than that of type-B, and the relation is the same of type-B and type-C. (3) The load-displacement curves of all kinds of short square CFST columns showed the descending section after the test reached the ultimate bearing capacity, but the absolute value of the tangent stiffness of the descending stage decreased gradually, and the final curve tended to be gentle. It showed that the axial bearing capacity and axial compression stiffness of short square CFST columns had a certain degree of degradation after reaching the axial compression bearing capacity, but the degradation rate gradually slowed down.

To compare the effects of stiffening ribs with or without holes on short square CFST columns, the relationship diagrams between ultimate bearing capacity and specimen types and that between ultimate displacement and specimen types are drawn, respectively, in Figure 5. It could be seen from the diagram that both types of strengthening methods can effectively increase the bearing capacity and ultimate displacement of the short column, in which the straight rib 
TABLE 2: Limit load and corresponding displacement of specimen.

\begin{tabular}{lccc}
\hline Specimen number & SCA-1 & SCA-2 & SCA-3 \\
\hline Ultimate load $(\mathrm{kN})$ & 6100 & 5089 & 8619 \\
Corresponding displacement $(\mathrm{mm})$ & 4.95 & 3.77 & 4.2 \\
Specimen number & SCB-1 & SCB-2 & SCB-3 \\
Ultimate load (kN) & 7793 & 6111 & 10997 \\
Corresponding displacement $(\mathrm{mm})$ & 5.45 & 4.09 & 6.81 \\
Load increment 1 (\%) & $1693(27.8)$ & $1022(20.1)$ & $2378(27.6)$ \\
Displacement increment 1 (\%) & $0.5(10.1)$ & $0.32(8.5)$ & $2.61(62.1)$ \\
Specimen number & SCC-1 & SCC-2 & SCC-3 \\
Ultimate load (kN) & 7088 & 5969 & 10096 \\
Corresponding displacement $(\mathrm{mm})$ & 6.53 & 4.2 & 7.76 \\
Load increment 2 $(\%)$ & $988(16.2)$ & $880(17.3)$ & $1477(17.1)$ \\
Displacement increment 2 $(\%)$ & $1.58(31.9 \%)$ & $0.43(11.4)$ & $3.56(84.8)$ \\
\hline
\end{tabular}

Note. The increment 1 was variation of B short columns relative to A short columns. The increment 2 was variation of C short columns relative to A short columns.

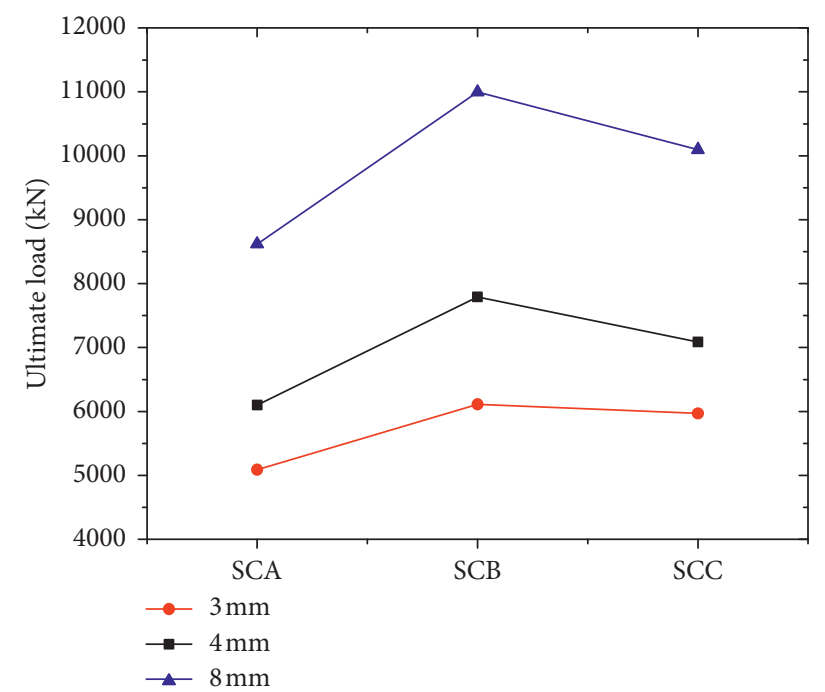

(a)

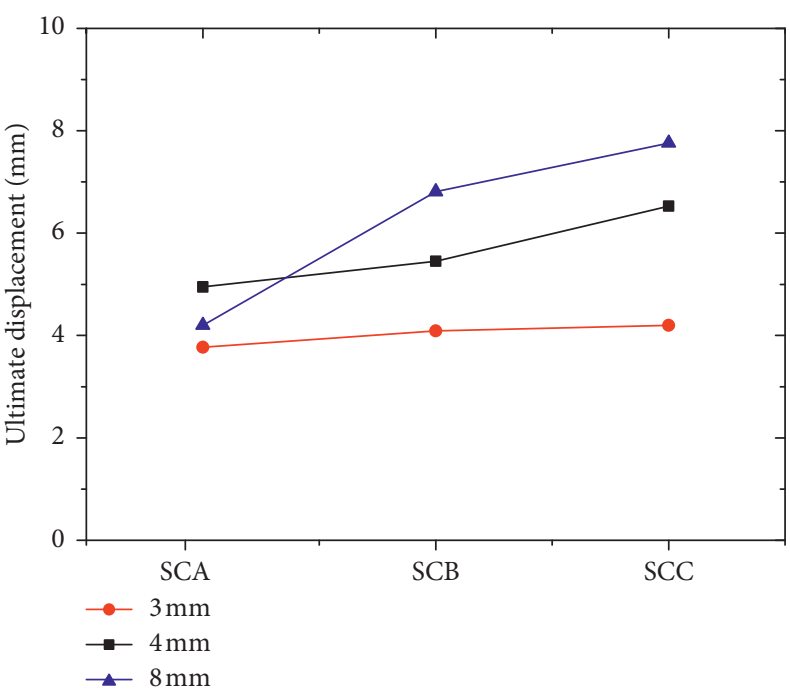

(b)

Figure 5: Change diagram of limit load and limit displacement.

can better improve the ultimate bearing capacity of the short column. The influence of perforated ribs on the deformation characteristics of short columns was greater.

\section{Simulation of the Stiffened Short Square CFST Columns}

4.1. The FEA Model. With the help of Abaqus, the authors built an FEA model, and the experiment was simulated by using plastic model for steel and concrete damaged plastic (CDP) model for concrete. The material parameters were measured from the test. An SC8R element was used for steel, while a C38R element was used for concrete. The mesh size was set at $30 \mathrm{~mm}$. Xu et al. [18] had set the friction coefficient between the steel and concrete as 0.5 .

4.2. The Analysis of Simulation Results. The deformation characteristics obtained from the simulation are shown in
Figure 6 and compared with those in Figures 2 and 3. It was found that the degree of buckling deformations on steel tubes from simulation was consistent with that in the test. In Figure 6, the deformation pattern of the steel tube was "single wave" and "double wave" depending on the specimen type, and the deformation was connected at the corner. The plastic strain distribution diagrams of the concrete were consistent with the concrete failure in the test. It showed that the equivalent plastic of finite element analysis can well reflect the compressive failure of concrete inside, and it also verified the reliability of FEA.

Figure 7 shows the stress distribution of the core concrete, and it could be seen in the diagram that the stress distribution of the concrete in the core area was adjusted by the stiffeners. The confinement effect in type-B and type- $C$ was enhanced, and the stress distribution range and the distribution gradient of the core concrete were increased. The stress of the whole section of the specimen distributed more evenly. After stiffening, the peak stress of core concrete 


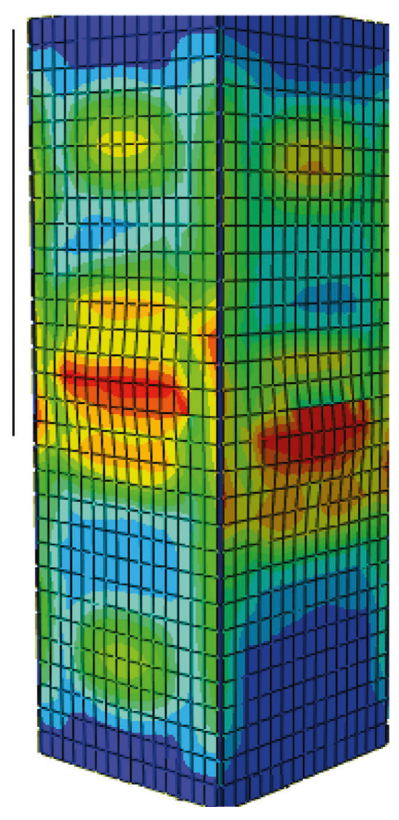

Type-A

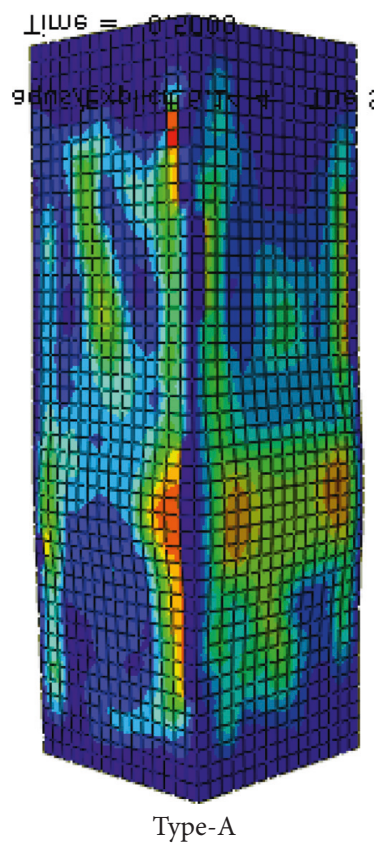

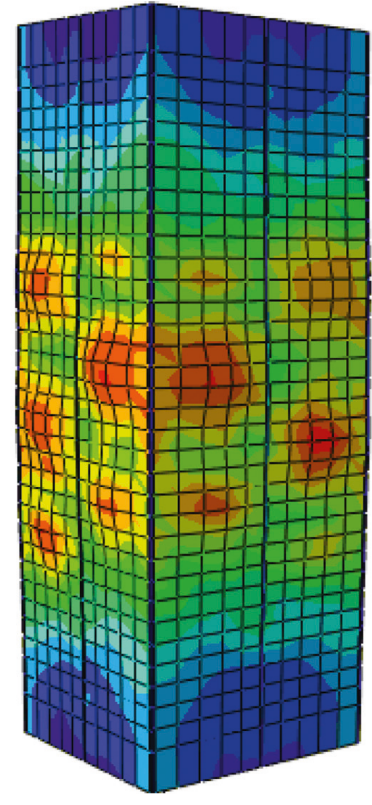

Type-B

(a)

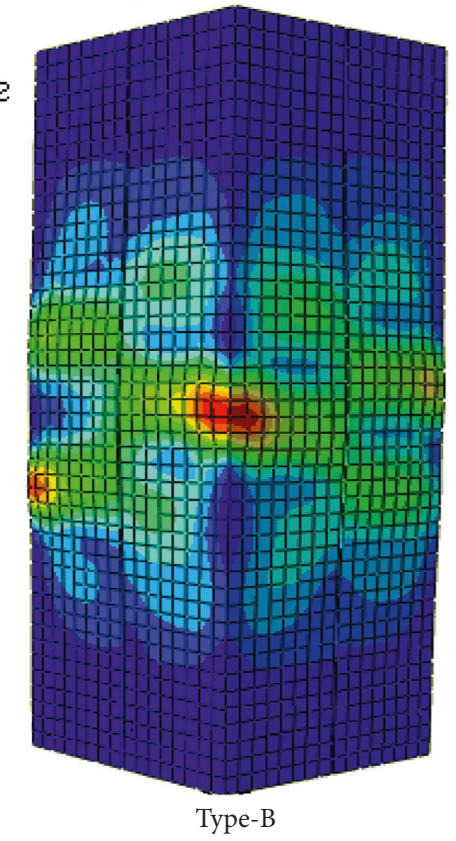

(b)

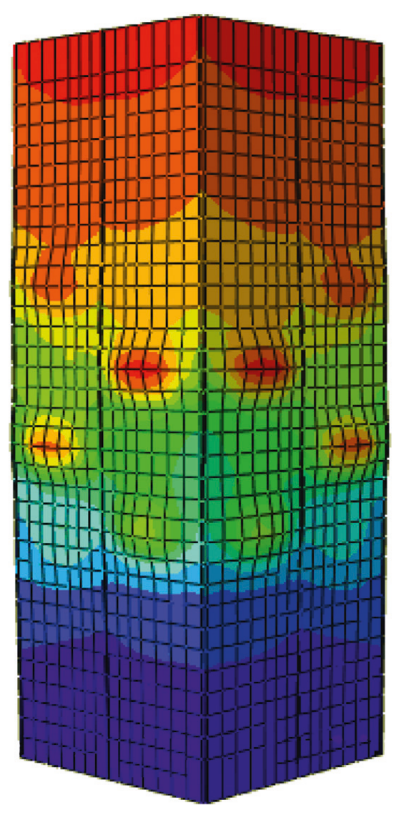

Type-C

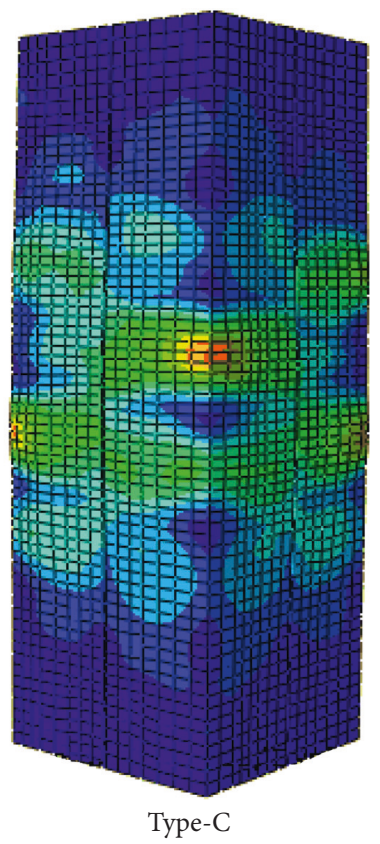

Figure 6: The failure of the specimen in simulation. (a) The failure strain of steel tubes. (b) The equivalent plastic strain of concrete.

was improved. In type- $\mathrm{B}$, the stress range of core region was slightly narrower, and the stress in core area was reducing. In type- $\mathrm{C}$, the stress distribution was regular shape, and the distribution gradient of stress was more obvious than that of type-B. The section stress distribution patterns varied in terms of the ribs with or without the holes and the diagram of the height $(h=300 \mathrm{~mm}$ and $h=450 \mathrm{~mm})$. The stress distribution on the sections without holes was a square concentric with a circle at the center, and the stress distribution pattern of every stress stage was paralleled. The stress distribution in the section with holes was more complex: the peak stress occurred in both the core area of the section and the hole areas of concrete. The whole distribution was also a square concentric with a circle at the center, but the pattern of stress distribution of different gradients was alternated layer by layer.

The stress distribution along the center line and the diagonal line in Figure 7 (at the height of $300 \mathrm{~mm}$ and $450 \mathrm{~mm}$ ) is plotted as curves in Figure 8, which indicated (1) the curves along the center with stiffeners were higher than 


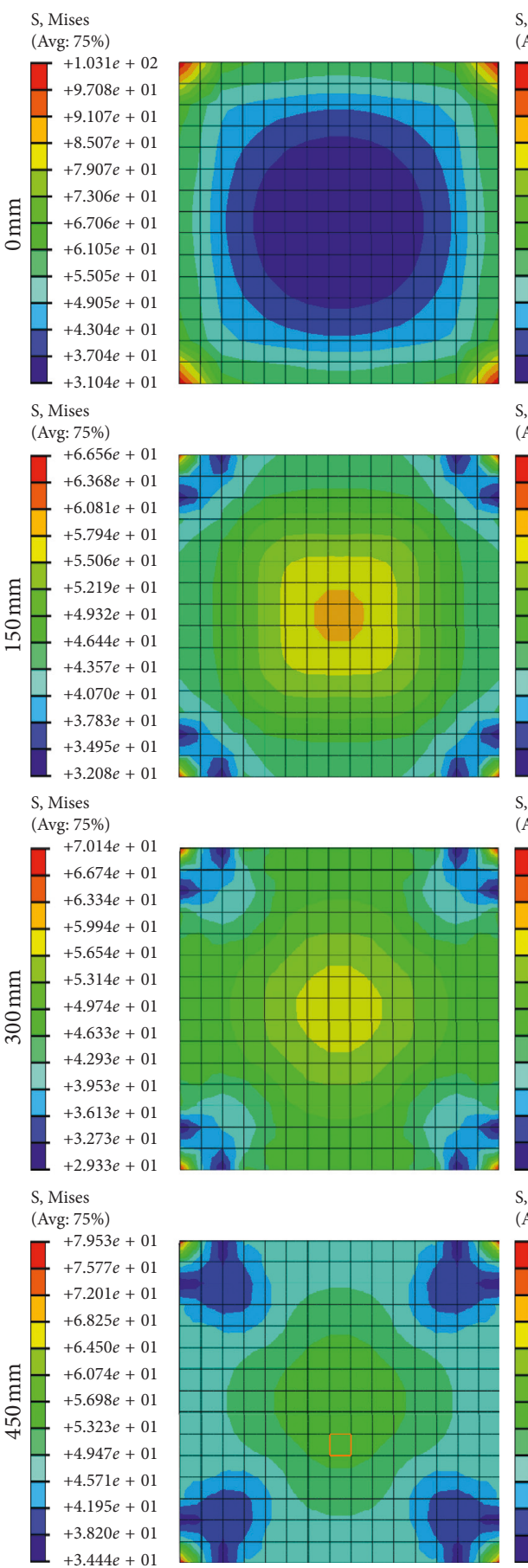

SCA-1
S, Mises

(Avg: $75 \%$ )

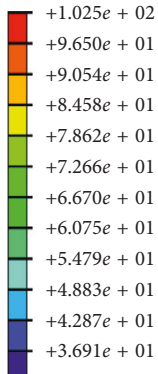

, Mises

(Avg: $75 \%)$

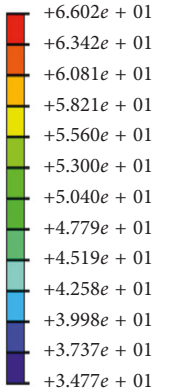

$\mathrm{S}$, Mises

(Avg: 75\%)

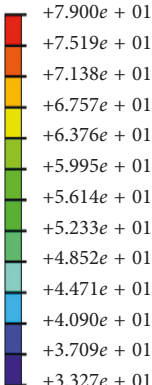

$\mathrm{S}$, Mises

(Avg: 75\%)

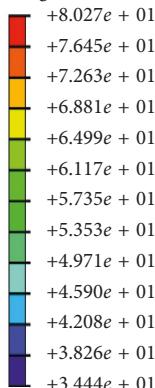

$+3.444 e+01$
S, Mises

(Avg: $75 \%$ )

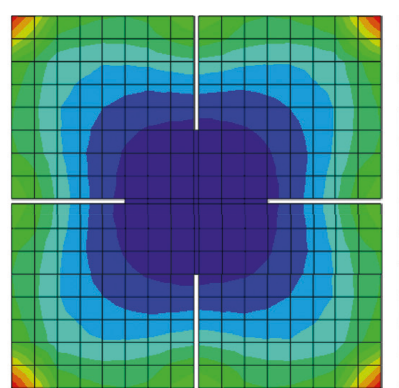

$+9.204 e+02$
$+8.684 e+01$
$-8.165 e+01$
$+7.646 e+01$
$+7.127 e+01$
$+6.608 e+01$
$-6.089 e+01$
$-5.570 e+01$
$+5.050 e+01$
$+4.531 e+01$
$+4.012 e+01$
$+3.439 e+01$

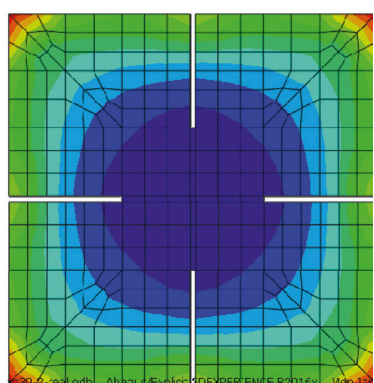

$\mathrm{S}$, Mises

(Avg: $75 \%)$

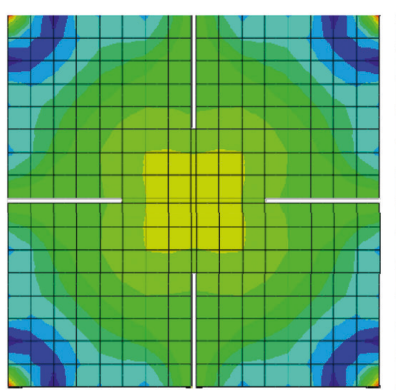

$+5.829 e+01$
$+5.573 e+01$
$+5.317 e+01$
$-5.061 e+01$
$+4.805 e+01$
$+4.548 e+01$
$+4.292 e+01$
$-4.036 e+01$
$+3.780 e+01$
$+3.524 e+01$
$+3.268 e+01$
$+3.021 e+01$
$+2.755 e+01$

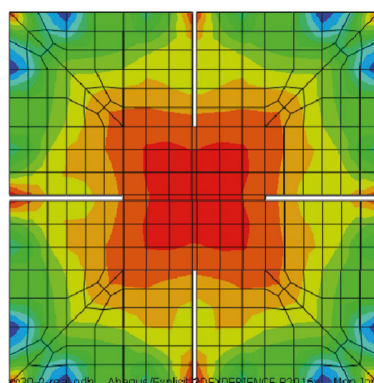

$\mathrm{S}$, Mises

(Avg: 75\%)

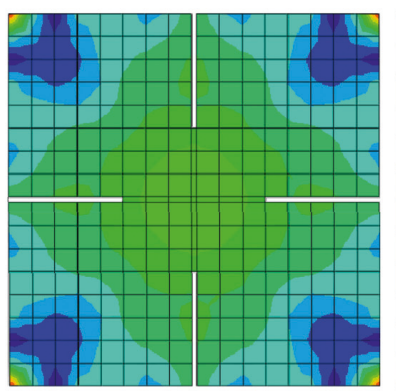

T $+6.899 e+01$

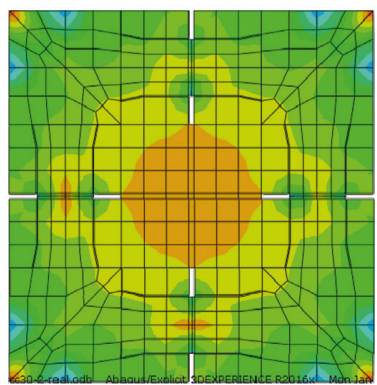

S, Mises

(Avg: 75\%)

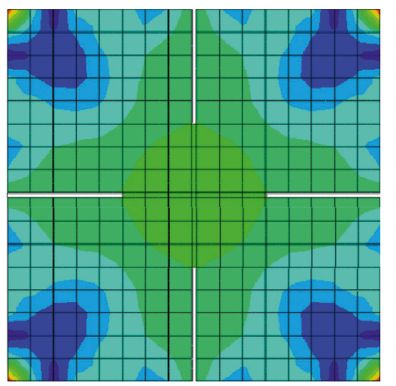

SCB-1

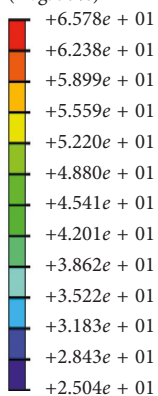

$+2.504 e+01$

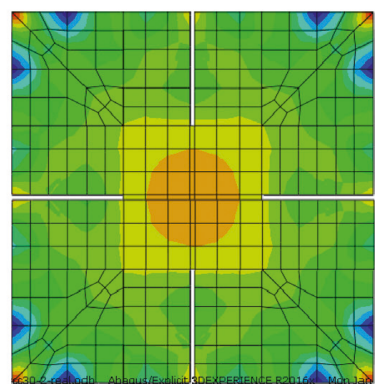

SCC-1

FIGURE 7: The stress distribution on section of the concrete with different heights.

that of type-A. The stiffeners had obvious effect on improving the stress at the middle of the side (the stress value of SCB was $6 \mathrm{MPa}$ more than SCA at $300 \mathrm{~mm}$ height, while SCC could improve $10 \mathrm{MPa}$ more at $450 \mathrm{~mm}$ height). (2) The holes cut down the value of stress at the corners, as the curves of SCC were the lowest at the corners of the tube (the stress value of SCC was $20 \mathrm{MPa}$ less than that of the highest). (3) All the stress values of stiffened specimen were lower than that of SCA as the curves shown at the core area.

\section{Calculation of Bearing Capacity of Reinforced Concrete-Filled Square Steel Tube Short Columns}

The concrete stress distribution in Figure 7 showed that there was stress concentration in the corners and the middle of the sides of both type-B and type-C, while the stiffeners could improve the buckling performance of steel tubes, so the effect of stiffeners for bearing capacity must be 

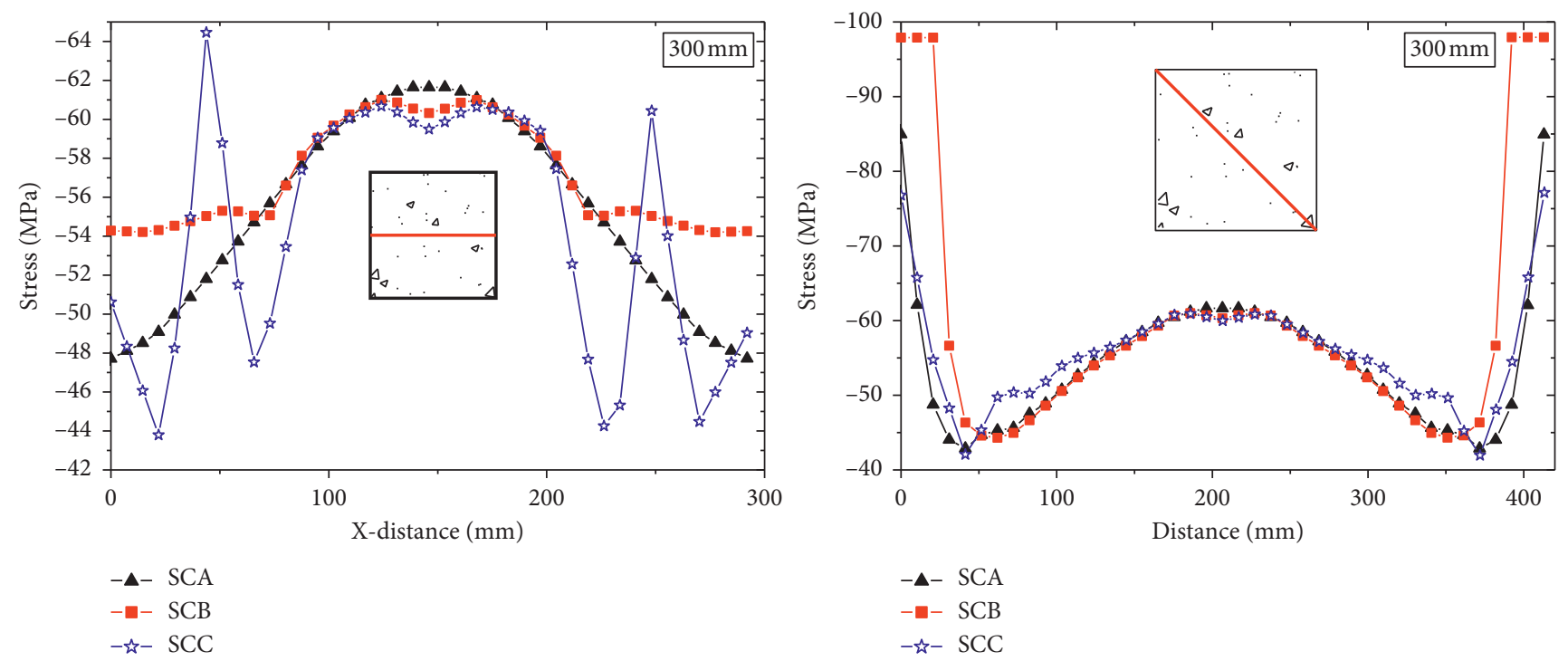

(a)
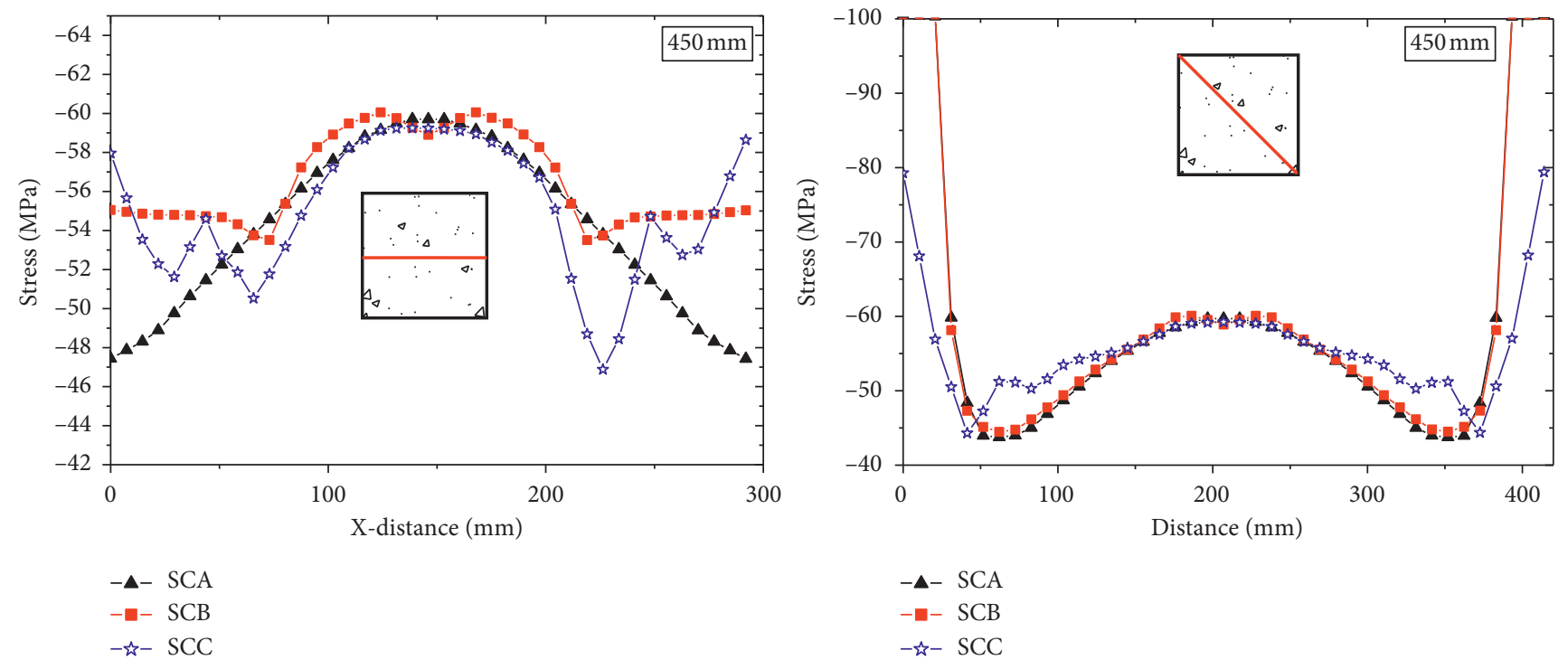

(b)

Figure 8: Diagram of stress distribution of concrete. (a) Stress distribution curve of center line and diagonal line at $300 \mathrm{~mm}$. (b) Stress distribution curve of center line and diagonal line at $450 \mathrm{~mm}$.

considered during the calculative process, and steel tube and concrete also affect the bearing capacity. So, the bearing capacity $N_{u}$ can be written as

$$
N_{u}=N_{C}+N_{S}+N_{L E}
$$

where $N_{C}$ is the bearing capacity of core concrete, $N_{C}=f_{c} A_{C} ; N_{S}$ is the bearing capacity of external steel tube, $N_{S}=f_{S} A_{S}$; and $N_{L E}$ denotes the strengthening of the bearing capacity of members.

The stiffened specimen's stress distribution is quite different from that of type-A: the values of stress were increased by the ribs, as is shown in Figure 7. The stiffener can be regarded as a $\mathrm{T}$-shaped member in the tube, and the bearing capacity of this T-shaped members can be obtained according to the standard of steel structure as

$$
N_{L E}=\frac{\pi^{2} E_{S} I}{l^{2}},
$$

where $E_{S}$ is the elastic module of the steel in the tube; $I$ is the module of bending section for the stiffeners; and $l$ is the effective length of stiffeners.

It is necessary to find out the effective width $\left(b_{e}\right)$ of the flange in the T-shaped member when calculating the parameter $I$ in accordance with the standard, it is revised to

$$
\begin{aligned}
\frac{b_{e}}{b} & =0.65 \sqrt{\frac{f_{o l}}{f_{y}}}, \\
f_{o l} & =\frac{\pi^{2} E_{C}}{12\left(1-\mu^{2}\right)} \times \frac{k}{(b / t)^{2}},
\end{aligned}
$$


TABLE 3: Comparison of calculated bearing capacity and finite element bearing capacity.

\begin{tabular}{lccc}
\hline Specimen number & $N_{u}(k \mathrm{~N})$ & Experimental bearing capacity $N_{u^{\prime}}^{\prime}(\mathrm{Kn})$ & $\alpha=N_{u} / N_{u^{\prime}}^{\prime}$ \\
\hline SCA-1 & 6100 & 6040 & - \\
SCB-1 & 6798 & 6768 & 1.00 \\
SCC-1 & 7088 & 6489 & 1.09 \\
SCA-2 & 5958 & 5368 & - \\
SCB-2 & 5984 & 5791 & 1.03 \\
SCC-2 & 5969 & 5616 & 1.06 \\
SCA-3 & 8619 & 7696 & - \\
SCB-3 & 10997 & 10820 & 1.02 \\
SCC-3 & 9566 & 10198 & 0.94 \\
\hline
\end{tabular}

where $b$ is the length of the side; $t$ is the thickness of the rib; $k=10.31 ; f_{y}$ is the steel yield strength; $\mu$ is the Poisson ratio of the steel; and $E_{C}$ is the elastic module of the concrete inside.

Equation (3) should be used to find out the effective width $\left(b_{e}\right)$, which can be introduced into Equation (2) to find out the bearing capacity of the T-shaped member $\left(N_{L E}\right)$ and subsequently get the bearing capacity of the specimen $\left(N_{u}\right)$ by Equation (1). Then, put all the results into Table 3. $\alpha$ is the ratio of calculated results to test results. The average ratio was 1.02, and the dispersion coefficient was 0.042 , which indicated that the calculated result was in good agreement with the test result.

Then, the bearing capacity of the test specimens is worked out according to the existing standards (NDBJ, NACI, NBS5400, NEC3, NCECS), and the values are given in Figure 9. It is evident that the calculation results of the formulas proposed in this paper are in better agreement with the test results compared with the calculation method of bearing capacity in the existing standards.

\section{Summary and Conclusions}

In order to limit the disengaging of short square CFST columns and strengthen the combined action of steel tubes and concrete, a reinforcing method of stiffener is put forward in this paper. The axial compression performance and mechanism are studied through experiments employing 3 types of specimens (no ribs, straight ribs with and without holes). Based on the experiments, the following conclusions are drawn:

(1) The stiffeners can improve the mechanical performance of specimens, such as the bearing capacity and the deformations. The failure mode changes clearly with the effect of stiffeners.

(2) The ultimate bearing capacity and the stretchability can be improved by the stiffeners, and the bearing capacity of type- $\mathrm{B}$ is the best, while the stretchability of type- $C$ was better than that of type-B.

(3) Stiffeners can change the buckling model of steel tubes, from "single wave" (type-A) to "double wave" (type-B and type-C).

(4) The FE model can give the stress distribution of the specimens. The stiffeners can change the stress distribution, improve the stress value in the middle

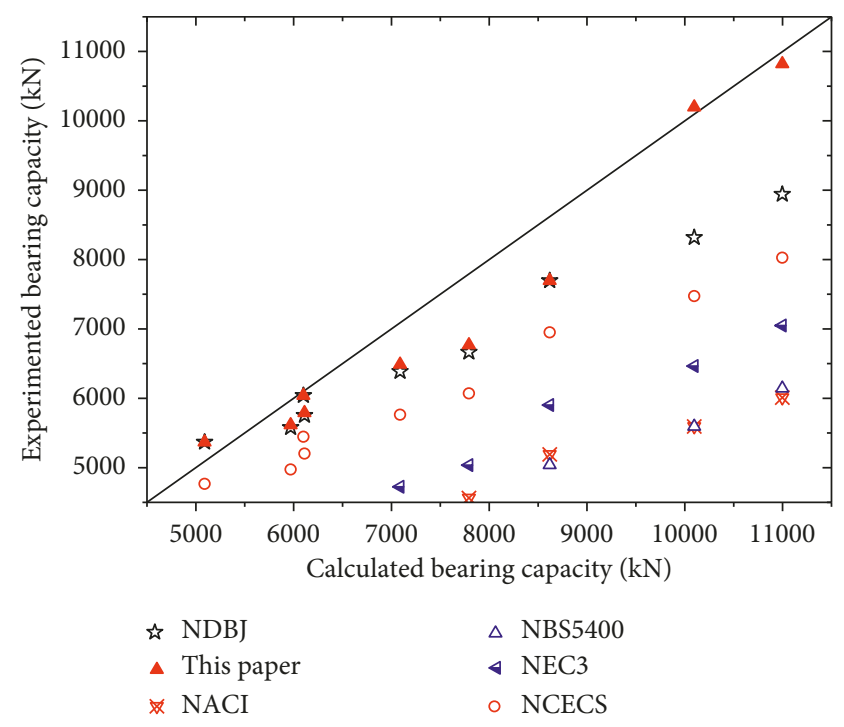

FIgURE 9: Comparison of results of calculation and finite element analysis.

of each side, and lower the stress value in the core area of the concrete.

(5) The calculation formulas proposed in this paper can more accurately describe the bearing capacity of stiffened steel tubular structures.

\section{Data Availability}

The data used to support the findings of this study are included within the article.

\section{Conflicts of Interest}

The authors declare that they have no conflicts of interest.

\section{Acknowledgments}

This study is supported by the National Natural Science Foundation of China (no. BK20160433), Foundation of Ministry of Housing and Urban-Rural Development (no. 2016-K8-009), Social development project of Jiangsu (no. BE2015658), Project supported by Natural Science Foundation of Universities in Jiangsu (no. 18KJD560006), and 
Jiangsu Province Transportation Development Road Bureau Project (no. 28 in 2017).

\section{References}

[1] L. H. Han, Concrete filled Steel Tube Structure: Theory and Practice, Science Press, Beijing, China, 2004.

[2] S. T. Zhong, Unified Theory of Concrete-Filled Steel Tube: Research and Application, Tsinghua University Press, Beijing, China, 2006.

[3] G. Y. Tu, D. H. Yan, and X. D. Shao, "Influence of debonding on ultimate bearing capacity of single tube concrete filled steel tubular arch bridge," Journal of Harbin Institute of Technology, vol. 42, no. 12, pp. 1999-2002, 2010.

[4] M. L. Wan, Study on Mechanical Properties of concrete filled Steel Tube Arch Rib joints with PBL Dumbbell, Chang'an University, Xi'an, China, 2012.

[5] S. C. Yang, F. M. Wang, and P. Qu, "Effect of core concrete stripping on mechanical properties of concrete-filled steel tubular members," Journal of Chongqing Jiaotong University, vol. 27, no. 3, pp. 360-365, 2008.

[6] J. Cai and Y. L. Long, "Axial Compression capacity of rectangular Concrete-filled Steel Tubular short columns with constraints," Acta Architectural Structure, vol. 30, no. 1, pp. 2-14, 2009.

[7] Y. Chen and Y. C. Zhang, "Study on the short columns of concrete filled square thin-walled steel tubes with oblique ribs under axial compression," Journal of Southeast University, vol. 36, no. 3, pp. 107-112, 2006.

[8] Y. C. Zhang and Y. Chen, "Experimental study and finite element analysis of square thin-walled concrete-filled steel tubular columns with straight ribs," Acta Architectural Structure, vol. 27, no. 5, pp. 16-22, 2006.

[9] C. L. Lei, "Development and test of new shear connector in steel-concrete composite bridge," Foreign Bridges, vol. 27, no. 2, pp. 64-68, 1999.

[10] H. C. Zhu, The Short-Column Bearing Capacity and Ductility of Concrete Filled Steel Tube with Constrained Pull Rod Square and Rectangular Cross Section are Discussed, South China University of Technology, Guangzhou, China, 2010.

[11] J. Cai and Y. L. Long, "Local buckling of steel plates in rectangular CFT columns with binding bars," Journal of Constructional Steel Research, vol. 65, no. 4, pp. 965-972, 2009.

[12] H. Huang, A. G. Zhang, Y. Li et al., "Experimental study and finite element Analysis of short columns filled with ribbed square steel tubular concrete under axial compression," Acta Architectural Structure, vol. 31, no. 2, pp. 75-82, 2011.

[13] D. L. Liu and W. M. Guo, "Axial load behavior of high strength rectangular concrete-filled steel tubular stub columns," Thin-Walled Structures, vol. 43, no. 8, pp. 1131-1142, 2005.

[14] C. Petrus, H. H. Abdul, A. Ibrahim et al., "Experimental behavior of concrete filled thin walled steel tubes with tab stiffeners," Journal of Constructional Steel Research, vol. 66, no. 7, pp. 915-922, 2010.

[15] B. C. Chen, "An overview of concrete and CFST arch bridges in China," in Proceedings of the Fifth International Conference on Arch Bridge, Madeira, Portugal, September 2007.

[16] J. H. Liang and X. L. Lu, "Experimental study on seismic behavior of concrete-filled square steel tubular columns with studs," Structure Engineering, vol. 28, no. 2, pp. 116-121, 2012.
[17] E. C. Oguejiofor and M. U. Hosain, "A parametric study of perfobond rib shear connectors," Canadian Journal of Civil Engineering, vol. 21, no. 4, pp. 614-625, 1994.

[18] B. Xu, Y. J. Liu, Z. Q. Li et al., "Finite element analysis of bearing capacity of concrete filled square steel tube columns under axial compression," Journal of Natural Science, vol. 34, no. 4, pp. 43-48, 2012. 


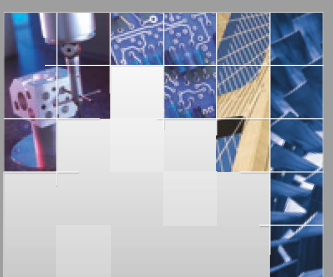

\section{Enfincering}
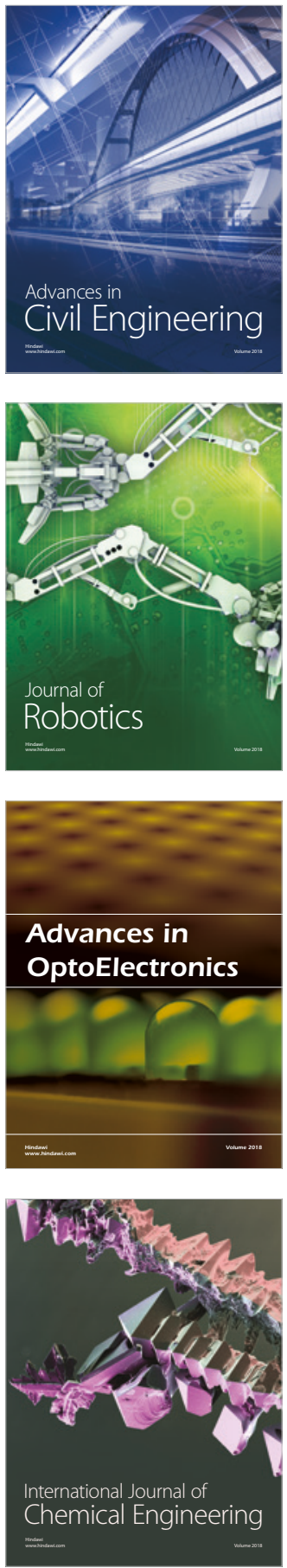

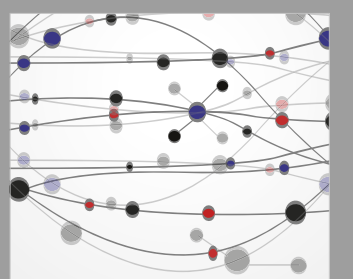

\section{Rotating \\ Machinery}

The Scientific World Journal

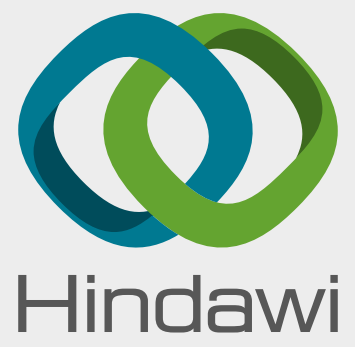

Submit your manuscripts at

www.hindawi.com
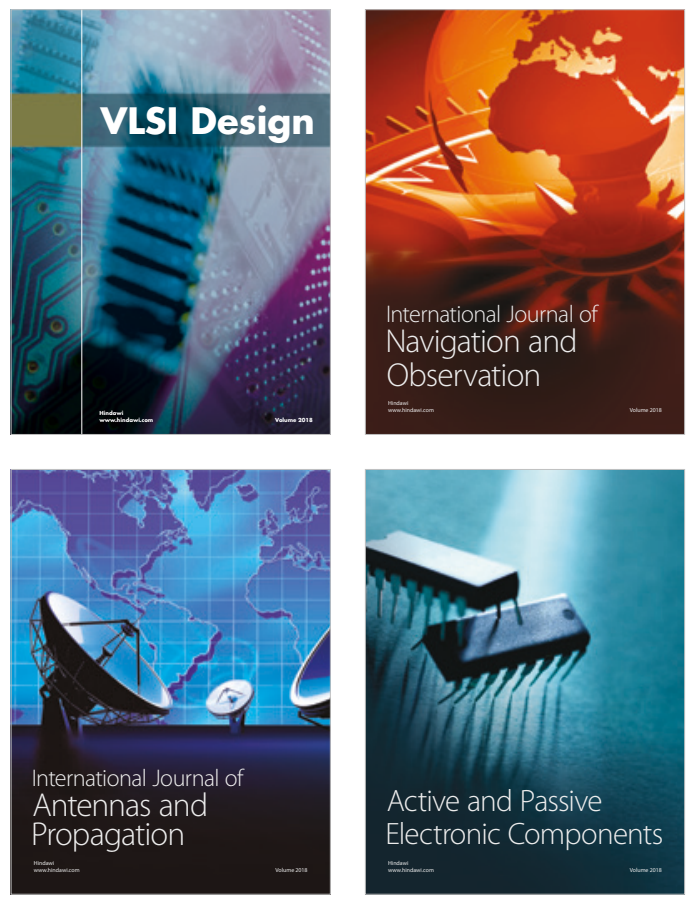
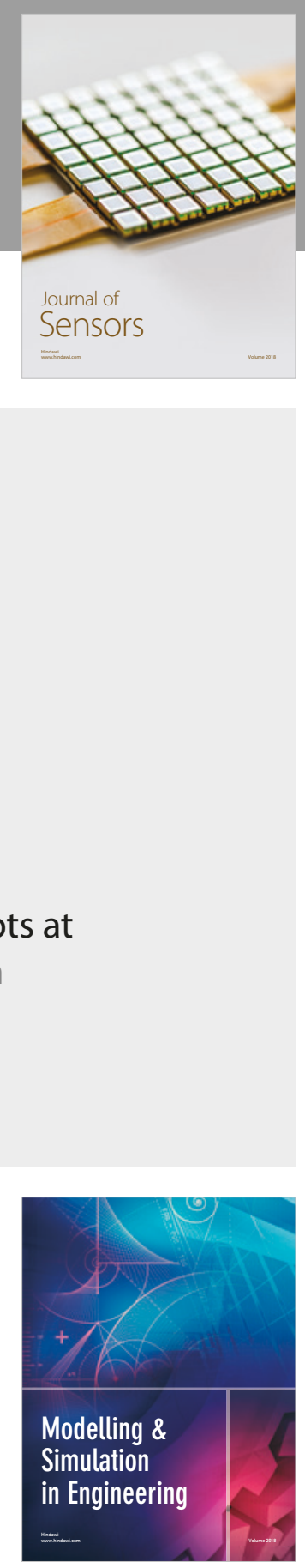

\section{Advances \\ Multimedia}
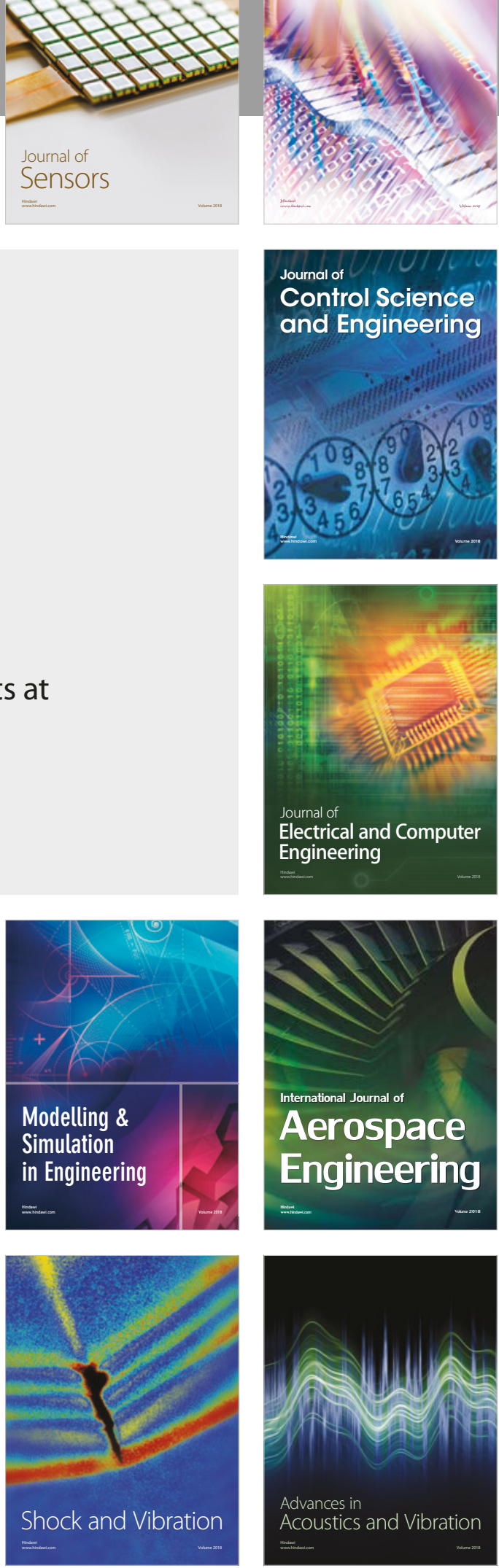